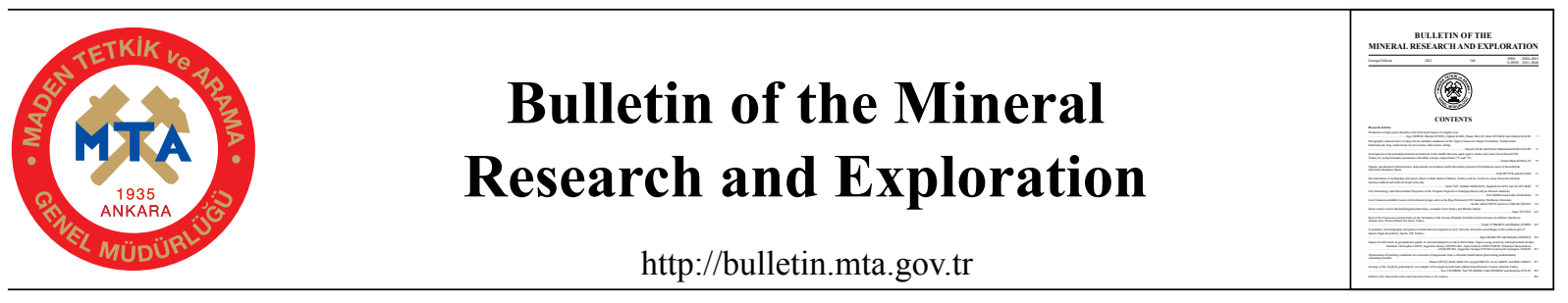

\title{
Production of high purity thorium oxide from complex ores leach liquor
}

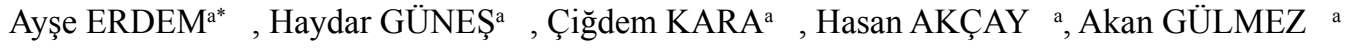 \\ and Zümrüt ALKAN $\mathbb{D}^{\text {a }}$ \\ ${ }^{\mathrm{a}}$ General Directorate of Mineral Research and Exploration, Mineral Analysis and Technology Department, 06530, Ankara, Turkey
}

Research Article

Keywords:

Thorium, Solvent

Extraction, Leach Liquor.

Received Date: 17.01.2020

Accepted Date: 25.03 .2020

\begin{abstract}
This paper investigates a method for separation and purification of thorium from leach liquors containing rare-earth elements (REE). Iron, which causes problems in the stage of thorium extracting, was first removed by using Adogen 464 solvent. Thorium was extracted with 30\% D2EHPA-in kerosene with 1/3 organic/aqueous ratio and stoichiometry of the thorium-D2EHPA complex was calculated as 1:2.6 from slope analysis. After the extraction, LREE and HREE were scrubbed from the extracted organic with $0.25 \mathrm{M} \mathrm{H}_{2} \mathrm{SO}_{4}$ and $6 \mathrm{M} \mathrm{HCl}$, respectively. Thorium oxalate was precipitated by oxalic acid and calcined at $1,050^{\circ} \mathrm{C}$. It was, after calcination, determined that purity of thorium oxide is $99.23 \%$, based on the ICP-OES analysis.
\end{abstract}

\section{Introduction}

Thorium is one of the radioactive elements that could be found within mineral structures in nature but cannot be directly used in nuclear reactors. Thorium can be converted to fissionable $\mathrm{U}^{233}$ isotope by several gradual neutron capture reactions (Kaya and Bozkurt, 2003). Thorium oxide, which has a high melting temperature of $3,300{ }^{\circ} \mathrm{C}$, is also used in non-fuel areas. Aerospace industry, lighting, ceramic production, high quality lenses, petroleum distillation, sulfuric acid and nitric acid production can be exemplified as usage fields of that. Additionally, Th-Mg alloys, thanks to their lightness, high temperature resistance and creep resistance, are used in aircrafts (Y1ld1z, 2016). More than forty minerals containing significant amount of thorium have been discovered, but only three of them can be used in thorium production; thorianite $\left(\mathrm{ThO}_{2}\right)$, thorite $\left(\mathrm{ThSiO}_{4}\right)$, and monazite [(Ce, $\left.\mathrm{La}, \mathrm{Nd}, \mathrm{Th}, \mathrm{Y}\right)$
$\mathrm{PO}_{4}$ ] (Du et al., 1993; Zhang et al., 2012; Demol et al., 2018). Monazite, which contains mineable rate of REE, is the most widespread and most commercially used one among the minerals containing Th. In addition to monazite, bastnäsite and xenotimeare also widespread REE minerals containing thorium (Ditz et al., 1990; Nasab et al., 2011).

In this study, Th-parisite was determined as the main mineral bearing thorium as a result of mineral liberation analysis of complex ore. Studies have shown that Th-parisite is the main mineral containing Th and REE in the ore. $99 \%$ of thorium element is in Th-parisite mineral.

Solvent extraction has become an important method for mineral processing studies after its usage during 1940's for uranium production. Thanks to this method, sufficient knowledge has been provided to be used in the production of various metals from

Citation Info: Erdem, A., Güneş, H., Kara, Ç., Akçay, H., Gülmez, A., Alkan, Z. 2021. Production of high purity thorium oxide from complex ores leach liquor. Bulletin of the Mineral Research and Exploration 164, 1-10. https://doi.org/10.19111/bulletinofmre.709316

*Corresponding author: Ayșe ERDEM, ayse.erdem@mta.gov.tr 
low grade ores, scraps, wastes and dilute aqueous solutions. It has facilitated, compared to old methods, the separation of chemically similar precious metals such as REE, Zr-Hf, Nb-Ta (Cox, 2004). The solvent extraction method takes place in three stages as loading the desired elements into the organic phase, scrubbing the co-added elements from the organic phase and stripping the desired elements from the organic phase (Ritcey and Ashbrook, 1979).

In recent years, cationic solvents have been used more for the production of REE, Th and $\mathrm{U}$, but the main problem in cationic solvents has been stripping of the desired metal from extracted organic. The stripping problem encountered after extracting by D2EHPA was overcome with Cyanex 572. Wang et al. have studied the process of separation of Th and REE from radioactive waste with Cyanex 572. In these processes, since Fe as main impurity is extracted with $\mathrm{Th}$, it prevents production of high purity $\mathrm{Th}$. The purity of Th is up to $99 \%$ in Fe-free feed solution (Wang et al., 2017). To extract Fe, Mishra et al., 2011 have used tricaprilylmethylammonium chloride (Aliquat 336), a quaternary amine, to extract Fe (III) from the chloride medium. It has been determined that extracting efficiencies increase as $\mathrm{HCl}$ and Aliquat 336 concentrations raise. As a result of the data obtained, Aliquat 336 makes it possible to extract the iron from the solution by extracting only the iron onto the organic phase (Mishra et al., 2011). In terms of this, Saji and Reddy investigated the synergic solvent extraction method to extract ironfrom chloride liquor obtained from wastes. They tried different ratios oftributyl phosphate (TBP) + methyl isobutyl ketone (MIBK) to produce high purity iron chloride and were able to achieve the highest synergic effect by using \%70 TBP + \%30 MIBK (Saji and Reddy, 2001). On the other hand, Sahu and Das investigated the synergistic solvent extraction of solutions containing iron over $100 \mathrm{~g} / \mathrm{L}$. They analyzed the synergistic effect of D2EHPA and TBP solvents in benzene and achieved the highest synergy coefficient with $40 \%$ TBP $+20 \%$ D2EHPA. Based on the information in this study, it was concluded that TBP additive facilitates stripping during the stripping phase (Sahu and Das, 1997).

The separation of Th and $U$ from REE with 2-ethylhexyl phosphoric acid mono 2-ethylhexyl ester (PC-88A) has been studied by Dinkar et al., 2012. During extracting studies, Th was completely taken into organic phase. Different chemicals have been used for stripping and carbonates have been identified as the best stripping chemicals (Dinkar et al., 2012). Bahri et al. (2018) have studied the extraction and purification of Malaysian monazite. Purification was carried out with chemical processes and solvent extraction. $98.85 \%$ purity of $\mathrm{ThO}_{2}$ was produced from nitric acid medium (Bahri et al., 2018; Salehuddin et al., 2019). Th production from monazite was carried out by Ali et al., 2007 in eight stages with Aliquat 336 from nitric acid medium. The stripping experiments were performed in 5 steps with $\mathrm{HCl}$ and the Th recovery efficiency from leach liquor was calculated as $97 \%$ (Ali et al., 2007). Thorium and REE separations have also been worked in a sulfuric acid environment by $\mathrm{Li}$ et al., 2004 and it resulted with thorium extracting by using primary amine (N1923). Before extracting REE from the medium, $\mathrm{MgO}$ was used to extract $\mathrm{Fe}$ and REE were extracted with D2EHPA and stripped with $\mathrm{HCl}$ (Li et al., 2004).

After stripping, thorium with high efficiency can be precipitated with the help of oxalic acid. Different volumes of leach liquor and oxalic acid have been tested by Güneş et al. (2019) to selectively precipitate thorium. The precipitation of Th with the lowest level of REE content was achieved by amount of $12 \%$ oxalic acid by volume (Güneş et al., 2019). The kinetics of the thermal degradation required for the conversion of thorium oxalate to thorium oxide and the decomposition temperatures were investigated by Aybers (1998). At this stage, the conversion temperature of thorium oxalate to thorium oxide has been determined as $410^{\circ} \mathrm{C}$ (Aybers, 1998). The effects of calcination temperature and temperature on crystal size were investigated by D'Eye and Sellman (1955). It was determined that thorium oxide calcined at temperatures lower than $400{ }^{\circ} \mathrm{C}$ is more hygroscopic than those calcined at higher temperatures (D'eye and Sellman, 1955).

In this study, high purity of $\mathrm{ThO}_{2}$ production was achieved by using Th-parisite ore for the first time in the literature. Solvent extraction has been performed by using Adogen 464 to remove iron which is the element that causes problems with extracting and purity of Th. Thorium extracting with D2EHPA from the Fe-free solution was performed in $94 \%$ efficiency. The REE extracted to organic phase with Th were scrubbed first with dilute sulfuric acid and then with concentrated 
hydrochloric acid. In the phase of obtaining $\mathrm{ThO}_{2}$, it was precipitated with oxalic acid and calcined.

\section{Experimental Studies}

\subsection{Leach Liquor ve Chemicals}

The ore, which is required to obtain the solution used in solvent extraction processes, was concentrated and extracted by General Directorate of Mineral Research and Exploration (MTA). The chemical composition of chlorinated leach liquor is presented in table 1. The LREE class referenced in table 1 consists of $\mathrm{La}, \mathrm{Ce}, \mathrm{Pr}, \mathrm{Nd}, \mathrm{Sm}$ and Eu elements, and the HREE class consists of $\mathrm{Gd}, \mathrm{Tb}, \mathrm{Dy}, \mathrm{Ho}, \mathrm{Er}, \mathrm{Tm}, \mathrm{Yb}, \mathrm{Lu}$ and Y elements. The brand of di-2-ethylhexyl phosphoric acid (D2EHPA), methyltrialkyl C8-C10 ammonium chloride (Adogen 464), decyl alcohol (1-Decanol) and tributyl phosphate (TBP) is Merck. On the other hand, brand of bis 2,4,4-trimethylpenyl phosphinic acid (Cyanex 272), Cyanex 572 and trioctyl phosphine oxide (TOPO) is Cytec Inc. Kerosene was obtained from local sources. All solvents were used directly without any purification. All acids which were used are Merck brand. All chemicals used are analytically pure and are supplied by MTA.

\subsection{Equipment}

Metal concentrations in solution were determined with Agilent 725 Series Inductively Coupled Plasma Optic Emission Spectrometer (ICP - OES) device. Electron microscope images and EDS analyzes were

Table 1- Chemical composition of leach liquor.

\begin{tabular}{|c|c|}
\hline Element & Concentration $\mathbf{( m g} / \mathbf{L})$ \\
\hline $\mathrm{Th}$ & 507.2 \\
\hline $\mathrm{U}$ & 40.6 \\
\hline $\mathrm{LREE}$ & 29,150 \\
\hline $\mathrm{HREE}$ & 265 \\
\hline $\mathrm{Fe}_{(\text {total })}$ & 5,490 \\
\hline $\mathrm{Al}$ & 3,000 \\
\hline $\mathrm{Ca}$ & 4,300 \\
\hline $\mathrm{Cu}$ & 12 \\
\hline $\mathrm{Mg}$ & 425 \\
\hline $\mathrm{Mn}$ & 1,570 \\
\hline $\mathrm{Pb}$ & 112 \\
\hline $\mathrm{Si}$ & 700 \\
\hline $\mathrm{Ti}$ & 32 \\
\hline $\mathrm{V}$ & 150 \\
\hline $\mathrm{Zn}$ & 210 \\
\hline
\end{tabular}

provided with the FEI Quanta 400 Scanning Electron Microscope (SEM-EDS) device.

\subsection{Method}

Cyanex 272, Cyanex 572 and D2EHPA solvents at different concentrations were tried to extract thorium directly from the leach liquor. With all three solvents, elements other than $\mathrm{Fe}$, Th, REE, $\mathrm{Cu}, \mathrm{Ti}, \mathrm{U}$ and $\mathrm{V}$ did not exhibit extracting behavior. The separation factor between iron and thorium is low with D2EHPA solvent, where the highest thorium extracting efficiency is observed and also, it was determined that other elements do not exhibit remarkable extracting behavior. Therefore, Fe removal studies were performed by using Adogen 464 and TBP before thorium extracting. Determining the most favorable Adogen 464 concentration was based on the separation of $\mathrm{Fe}$, Th, REE and impurities from each other.

Based on the information obtained from the preliminary experiments, thorium extracting was optimized with D2EHPA from the iron-extracted solution. It was also found that $\mathrm{REE}, \mathrm{Ti}, \mathrm{Cu}, \mathrm{V}$ and $\mathrm{U}$ elements were extracted as impurities during the thorium extracting. The optimization at this stage was based on high thorium extracting efficiency and low impurity extracting efficiency. Experiments were carried out at the mixing speed at which the phases were completely mixed. Mixing time of 15 minutes was determined to ensure the chemical balance in all of the experiments. The $\mathrm{pH}$ value of the leach liquor without $\mathrm{Fe}$ was measured as -0.58 and there was no application to change the $\mathrm{pH}$ value. The organic/ aqueous phase ratio was used as $1 / 1$ unless otherwise specified.

D2EHPA concentration was varied from $10 \%(0.3$ $\mathrm{M})$ to $50 \%(1.5 \mathrm{M})$ by volume in kerosene. D2EHPA concentrations above $50 \%$ are not suitable due to gel formation and undesired cp-extractions. The organic/ aqueous phase ratio was changed between $1 / 3$ and $3 / 1$ at a concentration of $30 \%$ D2EHPA. This ratio was found to be sufficient since a single stage extracting was achieved with a $94 \%$ efficiency.

Scrubbing processes were applied to reduce the effect of REE and other impurities extracted with thorium on the end product. Scrubbing was applied in varying concentrations of $\mathrm{HCl}, \mathrm{H}_{2} \mathrm{SO}_{4}$ and $\mathrm{HNO}_{3}$ to determine the acids and concentrations to be used 
in this process. As a result, two separate acids were used for LREE and HREE. It was observed that only high concentration of sulfuric acid is effective for thorium stripping. After stripping from the organic phase, precipitation was carried out with oxalic acid. The solid product was dried in the oven at $105^{\circ} \mathrm{C}$ and calcined in the oven at $1,050{ }^{\circ} \mathrm{C}$. Purity of $\mathrm{ThO}_{2}$ was determined in the ICP-OES device by the method of dissolving impurities.

\subsection{Data Processing}

Extracting efficiencies weretakeninto consideration to evaluate experimental data and the most suitable parameters for each step were determined according to the extracting efficiency values $(\mathrm{E} \%)$ calculated with the mass balance presented in equation 1 .

$$
\% E=\frac{C_{0}-C_{e}}{C_{0}} \times 100
$$

$C_{0}$ and $C_{e}$ represent initial and equilibrium concentrations, respectively. Distribution ratio and separation factor are represented in equation 2 and equation 3 , respectively.

$$
\begin{aligned}
& D_{A}=\frac{\left(C_{0}-C_{e}\right) V_{a}}{C_{e} V_{o}} \\
& \beta_{A / B}=\frac{D_{A}}{D_{B}}
\end{aligned}
$$

Aqueous and organic phase volumes, in equation 2 , are respectively represented as $V_{a}$ and $V_{o}, D_{A}$ represents the distribution ratio of 'A' element. The distribution rate is the main measurement parameter for solvent extraction processes and is determined by mass balance. ' $\mathrm{A}$ ' and ' $\mathrm{B}$ ' are different elements and $\beta_{A}$ represents the factor where'A element' separates from 'B element'.

\section{Experimental Results}

\subsection{Extraction of Iron}

During iron extraction, TBP and Adogen 464 solvents were tried and the effect of concentration on separation of iron and other impurities from thorium was investigated. The effect of concentration on separation factors is presented in figures 1 and 2 .

According to figures 1 and 2 , the highest separation factors for $\mathrm{Fe} / \mathrm{Th}$ and impurity/Th were obtained with

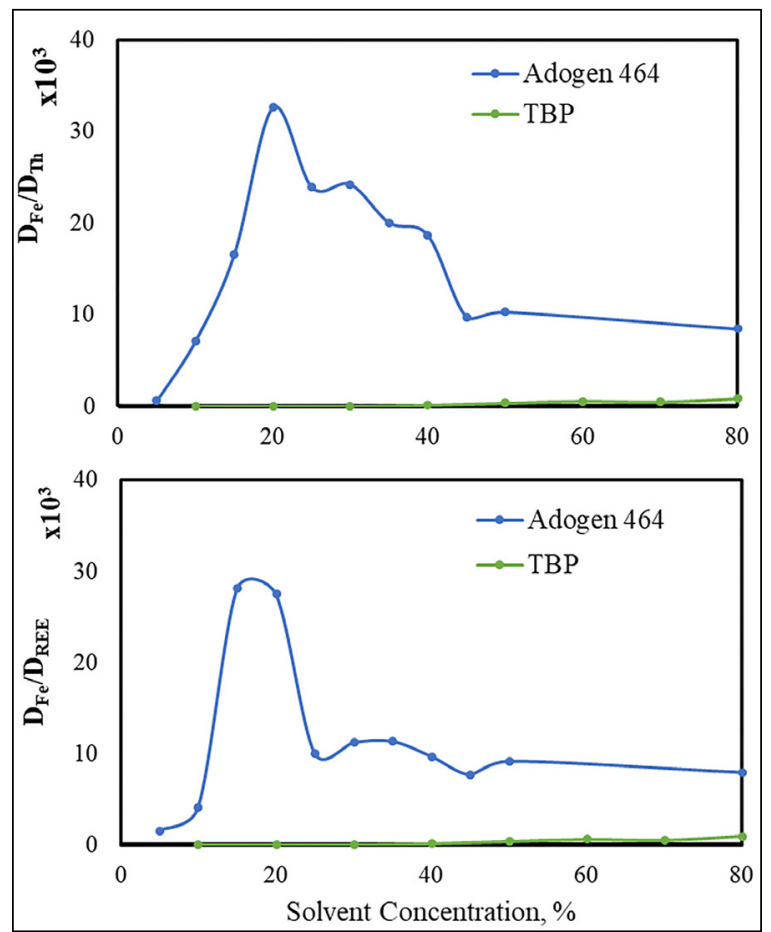

Figure 1- Separation factors of Fe/REE and Fe/Th according to different solvent concentrations.

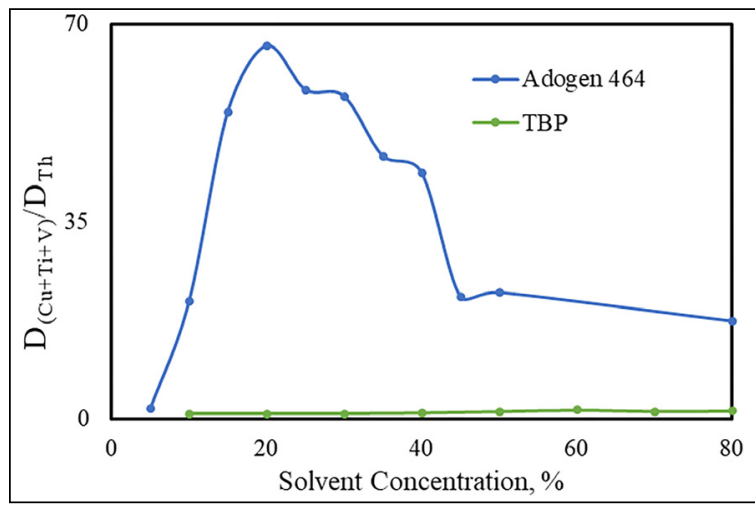

Figure 2- Separation factors of impurities $(\mathrm{Cu}+\mathrm{Ti}+\mathrm{V}) / \mathrm{Th}$ according to different solvent concentrations.

$20 \%$ Adogen in kerosene. Concentration of $20 \%$ Adogen 464 was preferred for further studies due to the highest level of separation factors between $(\mathrm{Cu}+\mathrm{Ti}+\mathrm{V})-\mathrm{Th}$. In figure 3 , the extracting efficiency of $\mathrm{Fe}, \mathrm{U}$ and impurities versus Adogen are graphed and the effect of solvent concentration on extracting efficiency was examined.

$\mathrm{Cu}, \mathrm{Fe}, \mathrm{Ti}, \mathrm{U}$ and $\mathrm{V}$ extracting efficiencies, which are other elements that will cause impurity during thorium production stage, are shown in figure 3. In addition, REE extracting rates remained below 1\% in all concentrations. As a result of the experiments 


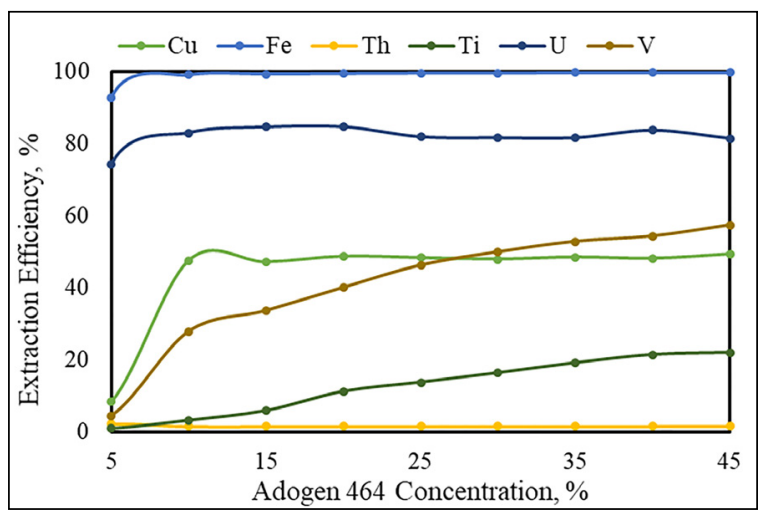

Figure 3- Effect of Adogen 464 concentration to the extraction efficiency.

performed, it was determined that all of the iron in solution can be removed with 20\% Adogen 464 solvent dissolved in kerosene. The aqueous phase obtained as a result of the process was used in later stages for thorium extracting.

\subsection{Exracting of Thorium}

D2EHPA was used to transfer the thorium from aqueous phase to organic phase, and extracting efficiencies in proportion to the solvent concentration in kerosene are presented in figure 4. HREE, other than $\mathrm{Dy}, \mathrm{Er}, \mathrm{Y}$ and $\mathrm{Yb}$, are not represented in the figures due to their low concentrations and low extracting efficiencies. The impurities having high extracting efficienciesand extracting efficiencies of $\mathrm{Cu}, \mathrm{Ti}$ and $\mathrm{U}$ that might cause impurity in the final product in later stages are represented.

When figure 4 is examined, Th, Ti and $\mathrm{U}$ exhibit similar extracting behaviors and indicate a high extracting efficiency even at low concentrations. Thorium extracting efficiency was determined as $95 \%$ at $30 \%$ D2EHPA usage rate. HREE were not extracted below 20\% D2EHPA concentration. In general, it has been observed that the extracting efficiency of elements other than $\mathrm{Cu}$ increases with the concentration of D2EHPA. Distribution rates were calculated only for Th, Ti, Y and Yb. Distribution rates calculated according to the equation 2 are shown in figure 5 .

Th, $\mathrm{Y}$ and $\mathrm{Yb}$ distribution rates increase logarithmically with D2EHPA concentration. This logarithmic relationship shows the first-order reaction between Th and D2EHPA. According to the slope analysis, stoichiometry of Th-D2EHPA was determined as 1:2.8. Stoichiometric ratios were calculated as 1:1.7, 1:1.5 and 1:2.5 for Ti, $\mathrm{Y}$ and $\mathrm{Yb}$, respectively.

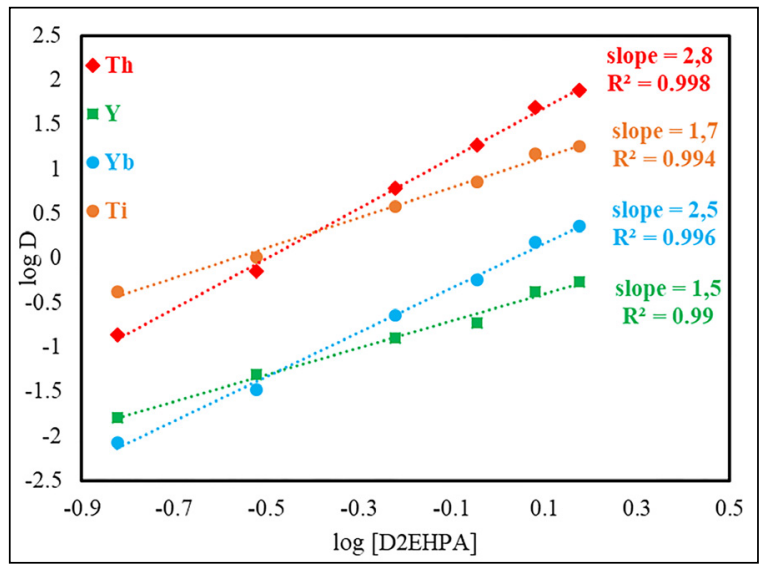

Figure 5- Logarithm of D2EHPA concentration vs logarithm of distribution ratios.

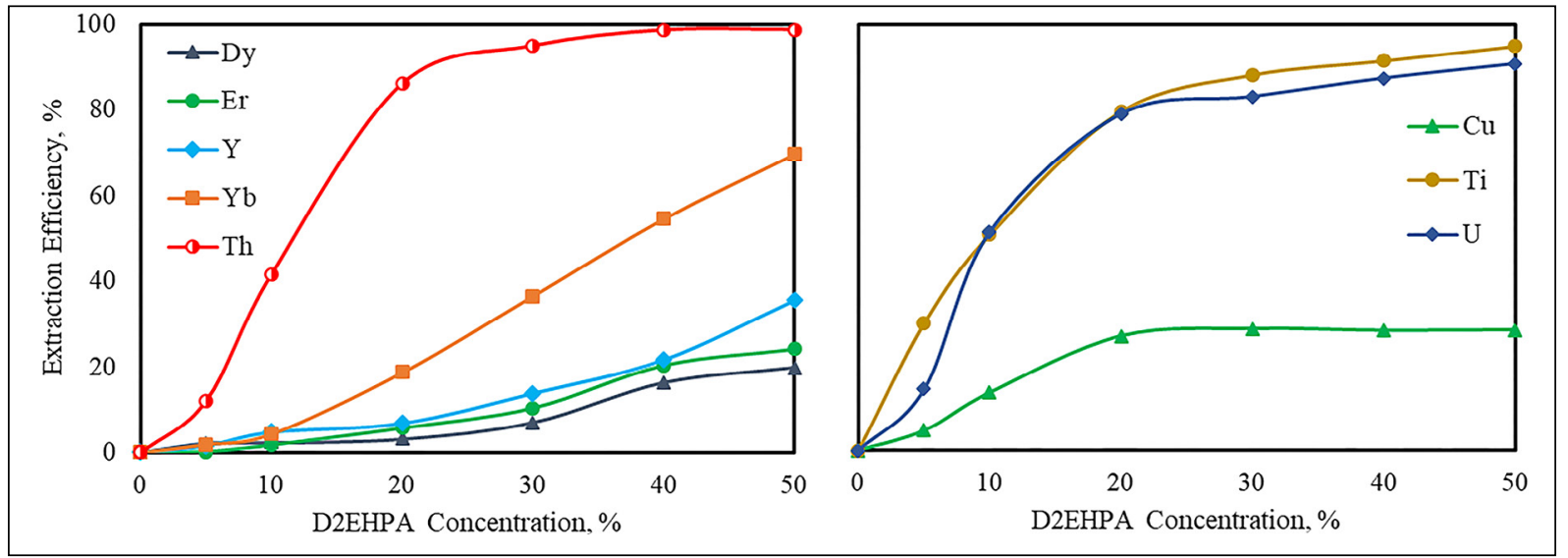

Figure 4- Effect of D2EHPA concentration to the extraction efficiencies of Th and HREEs. 
The separation factors, which are the ratio of distribution coefficients obtained by equation 2 , were calculated by equation 3 and the separation factors based on variable D2EHPA ratios are presented in figure 6 .

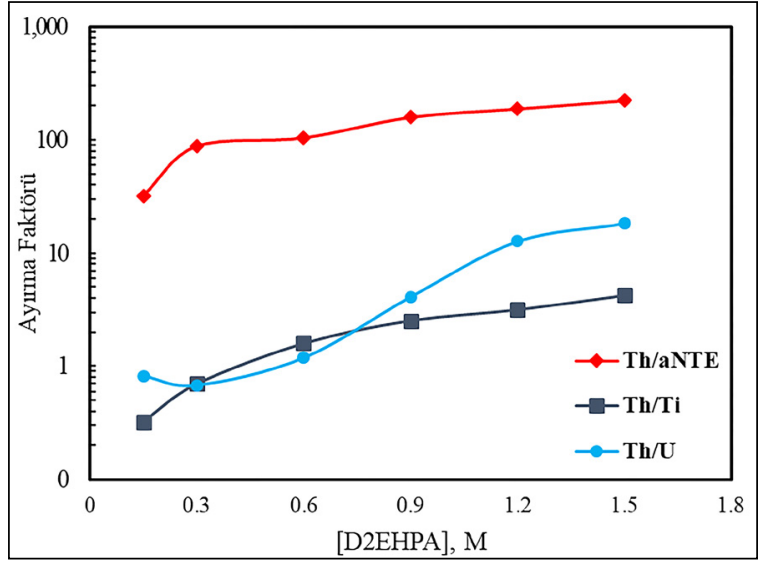

Figure 6- Separation factors between $\mathrm{Th} / \mathrm{Ti}, \mathrm{Th} / \mathrm{U}$ and $\mathrm{Th} / \mathrm{HREEs}$.

Considering the separation factors, D2EHPA concentration of $0.9 \mathrm{M}(30 \%)$ was determined as the most favorable parameter. For $U$ element, the separation factor remained constant at first, but did not show a positive change afterwards. According to the results, concentration of $30 \%$ D2EHPA was used to determine the most favorable organic/aqueous phase ratio. The results of the experiments carried out at rates ranging between $1 / 3$ and $3 / 1$ by volume are presented in table 2 .

Exracting efficiency increases directly proportional with the organic phase volume. Considering
Table 2- Extracting efficiencies of varying ratios of $\mathrm{O} / \mathrm{S}$.

\begin{tabular}{|c|c|c|c|c|c|}
\hline $\mathbf{O} / \mathbf{S}$ & Th, $\%$ & HREE, $\%$ & $\mathbf{T i}, \boldsymbol{\%}$ & $\mathbf{U}, \boldsymbol{\%}$ & $\mathbf{C u}, \mathbf{\%}$ \\
\hline $\mathbf{1 / 3}$ & 94 & 7 & 81 & 76 & 29 \\
\hline $\mathbf{1 / 2}$ & 95 & 11 & 87 & 87 & 29 \\
\hline $\mathbf{1}$ & 95 & 11 & 88 & 89 & 30 \\
\hline $\mathbf{2}$ & 98 & 23 & 98 & 94 & 30 \\
\hline $\mathbf{3}$ & 99 & 29 & 99 & 97 & 31 \\
\hline
\end{tabular}

the extracting efficiency of thorium, HREE and impurities, $1 / 3$ phase ratio has been determined as the most favorable ratio. In addition, as the organic phase volume decreases, it was observed that the elements that would create impurity are less extracted.

\subsection{Scrubbing of Impurities}

Scrubbing was applied during the removal of impurities loaded together to obtain purer thorium which is extracted in the organic phase. Scrubbing the impurities from the organic phase by using different acids and concentrations was examined and the relevant scrubbing efficiencies are presented in figure 7 .

According to the results obtained, $0.25 \mathrm{M}$ $\mathrm{H}_{2} \mathrm{SO}_{4}$ was used to scrub LREE with high efficiency. During the scrubbing experiments performed with $1 / 1 \mathrm{O} / \mathrm{S}$ ratio, concentration of scrubbing solution has been increased as scrubbing efficiency as LREE scrubbing efficiency has remained at $80 \%$ and a part of organic phase has been scrubbed by two part of acid so that, scrubbing efficiency has been raised to

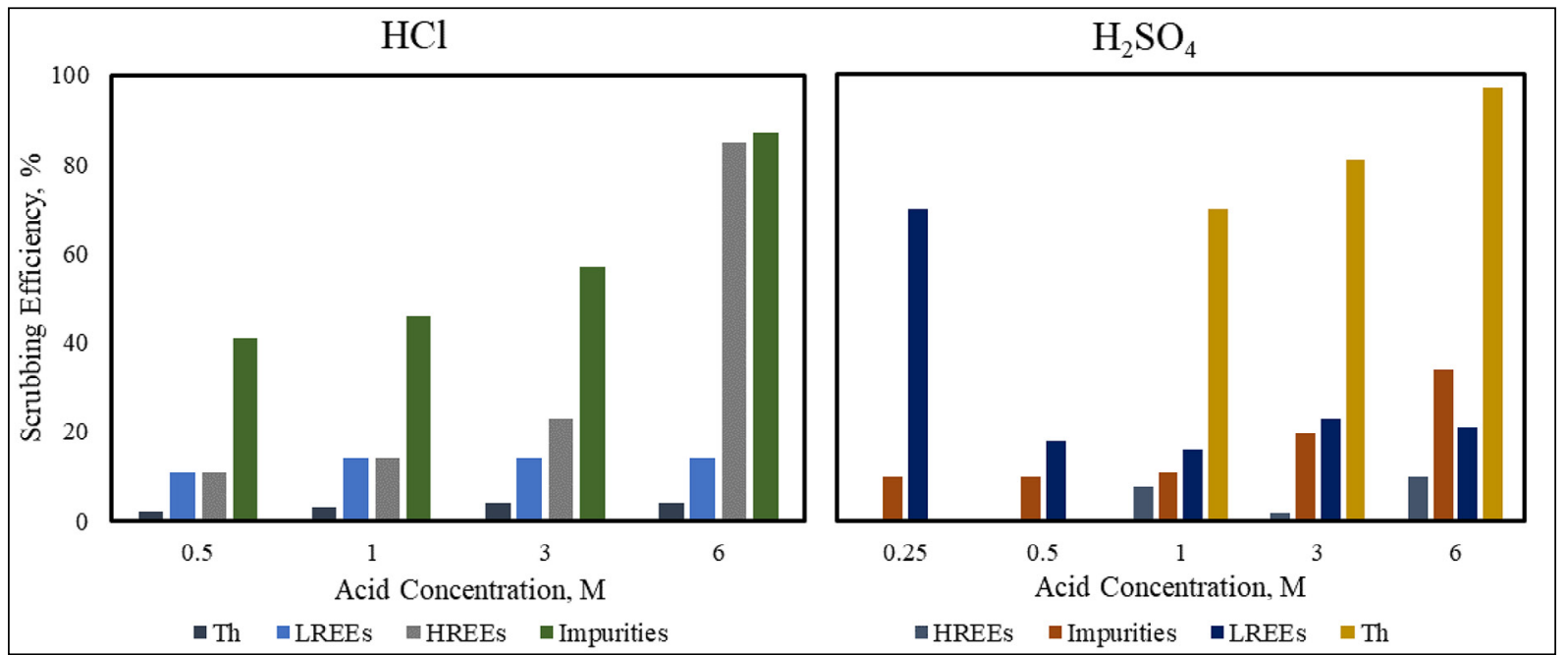

Figure 7- Scrubbing efficiency with varying acid concentrations. 
95\%. Scrubbing of HREE with high efficiency rates is possible with $6 \mathrm{M} \mathrm{HCl}$. Organic phase wasscrubbed with $0.25 \mathrm{M} \mathrm{H}_{2} \mathrm{SO}_{4}$ until LREE in organic phase disappear to increase the purity of HREE which are the side products to be produced. Afterwards, scrubbing process was continued until HREE in organic phase completely disappear. Concentrations and efficiencies of the solutions obtained are represented in table 3.

All of the elements causing impurity in scrubbed HREE were extracted by extracting $0.2 \mathrm{M}$ TOPO and HREE were obtained by precipitation from the remaining aqueous phase.

\subsection{Stripping of Thorium}

Considering the preliminary experiments and literature studies, stripping the thorium from the organic phase is only possible with concentrated $\mathrm{H}_{2} \mathrm{SO}_{4}$. It was observed that the phosphorus concentration in the aqueous phase increased with breaking down of organic phase due to increase in

Table 3- Chemical compositions and scrubbing efficiencies of scrubbing solutions

\begin{tabular}{|c|c|c|c|c|c|}
\hline $\begin{array}{c}\text { Acid and } \\
\text { Concentration }\end{array}$ & & Th & LREE & HREE & Impurity $^{*}$ \\
\hline \multirow{2}{*}{$\begin{array}{c}0.25 \mathrm{M} \text { of } \\
\mathrm{H}_{2} \mathrm{SO}_{4}\end{array}$} & $\begin{array}{c}\text { Concentration, } \\
\text { ppm }\end{array}$ & 0 & 271.5 & 0.1 & 3.6 \\
\hline & Efficiency, \% & 0 & 95.1 & 0.3 & 10.1 \\
\hline \multirow{2}{*}{$6 \mathrm{M} \mathrm{of} \mathrm{HCl}$} & $\begin{array}{c}\text { Concentration, } \\
\text { ppm }\end{array}$ & 5.2 & 5.2 & 40.0 & 2.7 \\
\hline & Efficiency, \% & 0.3 & 1.9 & 77.8 & 9.2 \\
\hline
\end{tabular}

${ }^{*} \mathrm{Cu}, \mathrm{Ti}, \mathrm{U}, \mathrm{V}$

Table 4- Stripping efficiencies and chemical compositions obtained from stripping experiments.

\begin{tabular}{|c|c|c|c|c|c|c|}
\hline $\begin{array}{c}\text { Acid } \\
\text { Concentration }\end{array}$ & & Th & $\mathbf{U}$ & LREE & HREE & Impurity $^{*}$ \\
\hline \multirow{2}{*}{$\mathbf{6} \mathbf{M ~ H}_{\mathbf{2}} \mathbf{S O}_{4}$} & $\begin{array}{c}\text { Concentration, } \\
\text { ppm }\end{array}$ & $1,270.4$ & 15.4 & 0.1 & 11.2 & 5.6 \\
\cline { 2 - 7 } & Efficiency, \% & 90.4 & 63 & 0.05 & 21.9 & 48.7 \\
\hline
\end{tabular}

*Cu, Ti, V the concentrations of acid solution by $9 \mathrm{M}$ or above. For this reason, $6 \mathrm{M}$ of $\mathrm{H}_{2} \mathrm{SO}_{4}$ was used for the thorium stripping stage. Obtained concentrations and calculated efficiencies are shown in table 4. According to the results from the stripping experiment performed with $6 \mathrm{M}$ of $\mathrm{H}_{2} \mathrm{SO}_{4}$, thorium stripping efficiency was found to be $90.4 \%$.

\subsection{Precipitation and Characterization}

The stripped thorium from the solution was precipitated by using $30 \%$ by volume, $0.5 \mathrm{~N}$ oxalic acid and the precipitate was dried at $105^{\circ} \mathrm{C}$ to obtain thorium oxalate dihydrate $\left[\mathrm{Th}\left(\mathrm{C}_{2} \mathrm{O}_{4}\right)_{2} \cdot 2 \mathrm{H}_{2} \mathrm{O}\right]$. The dried solid product was calcined at $1,050{ }^{\circ} \mathrm{C}$ to obtain thorium oxide $\left(\mathrm{ThO}_{2}\right)$. Characterization of the final product was carried out with ICP-OES and the results are presented in table 5. SEM images of thorium oxalate and thorium oxide are presented in figure 8 .

The proposed flow chart of the method is presented in figure 9.

Table 5- ICP-OES results.

\begin{tabular}{|c|c|}
\hline \multicolumn{2}{|c|}{ ICP-OES } \\
\hline Oxide & Percentage \\
\hline $\mathrm{Al}_{2} \mathrm{O}_{3}$ & 0,208 \\
\hline $\mathrm{CeO}_{2}$ & 0,061 \\
\hline $\mathrm{CuO}$ & 0,200 \\
\hline $\mathrm{SiO}_{2}$ & 0,004 \\
\hline $\mathrm{ThO}_{2}$ & 99,234 \\
\hline $\mathrm{TiO}_{2}$ & 0,016 \\
\hline $\mathrm{U}_{3} \mathrm{O}_{8}$ & 0,180 \\
\hline $\mathrm{Yb}_{2} \mathrm{O}_{3}$ & 0,091 \\
\hline
\end{tabular}




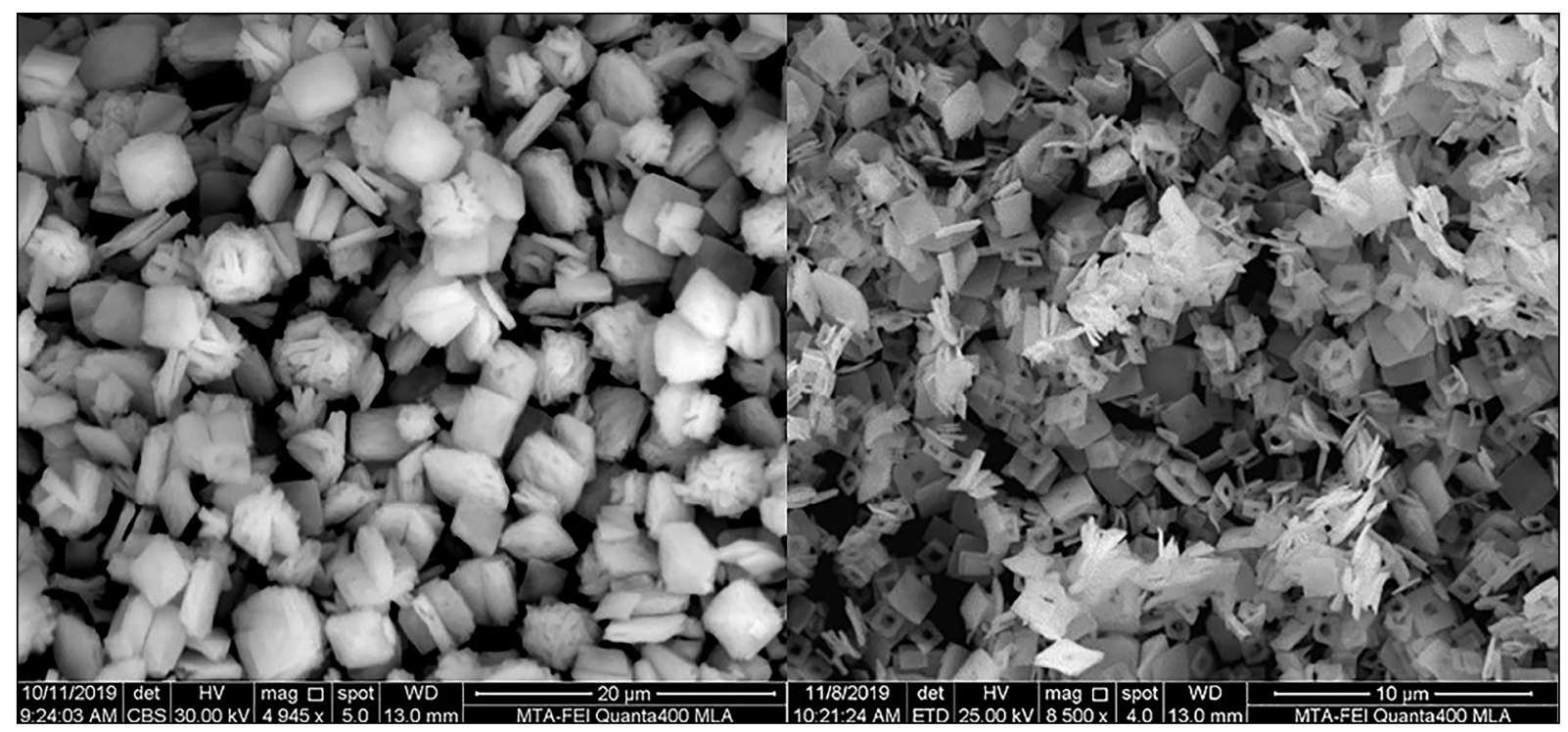

Figure 8- SEM image representing the thorium oxalate (left) and thorium oxide (right).

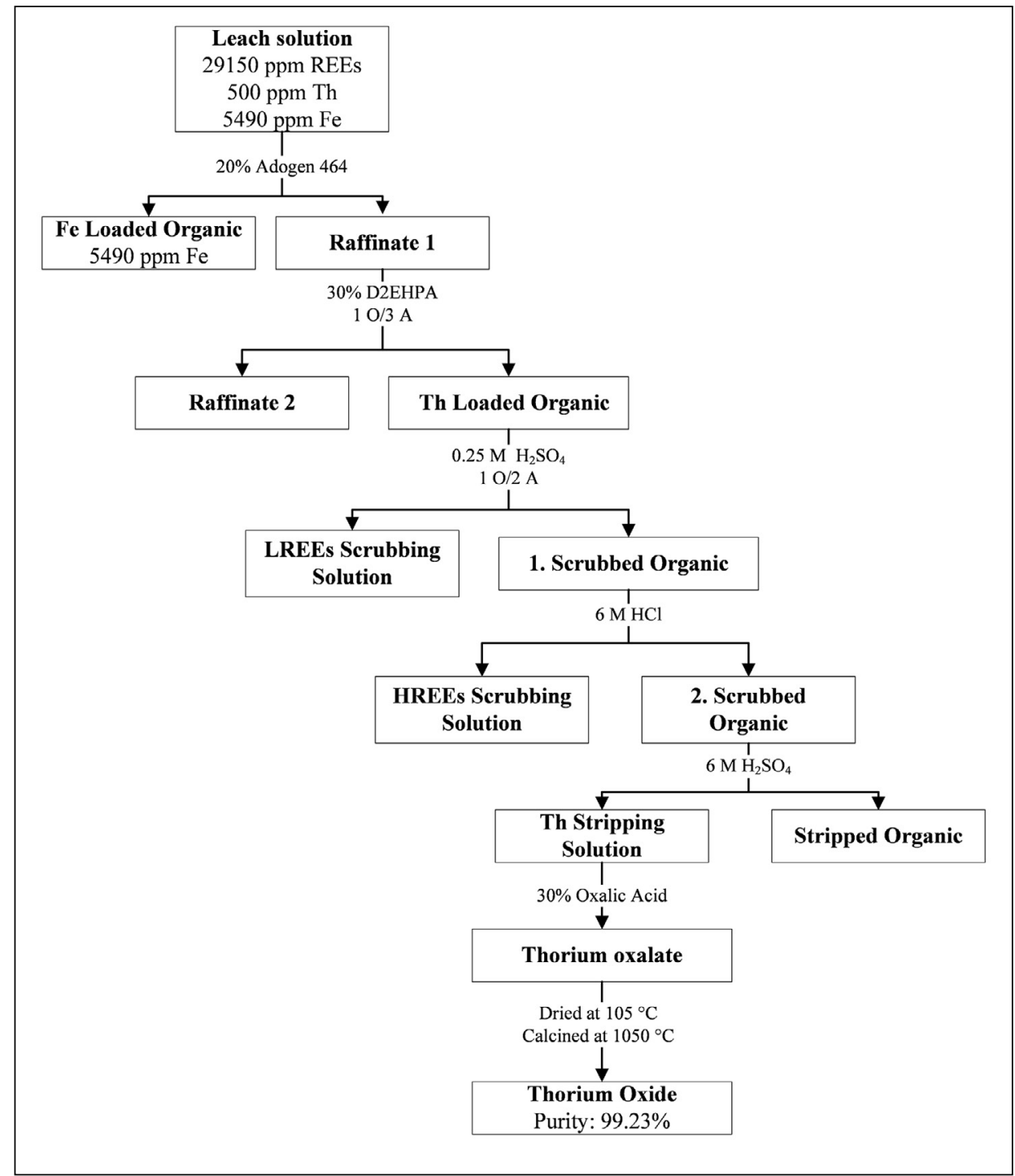

Figure 9- Flowchart of the process. 


\section{Discussions}

As can be seen in the literature research and preliminary experiments, selective thorium solvent extraction is not possible from chlorinated solutions containing iron. When the effects of solvents tested for iron extraction on extracting process were examined, it was found that iron extracting with Adogen 464 was more effective than TBP at lower solvent concentrations. Also, when the separation factors between Fe-Th, Fe-REE and $(\mathrm{Cu}+\mathrm{Ti}+\mathrm{V})$-Th are examined, Adogen 464 is superior to TBP solvent in terms of $\mathrm{Cu}, \mathrm{Ti}, \mathrm{V}$ and $\mathrm{U}$ extracting which could be found as impurity in the final product. As a result, the concentration of $20 \%$ Adogen $464(\mathrm{Cu}+\mathrm{Ti}+\mathrm{V})$ was preferred due to the highest levels of separation factors. Adogen 464, a quaternary amine, causes difficulties in application because of the third phase formation problem that is observed in other amine compounds as well. Therefore, experiments were carried out with 5\% decanol additive and the formation of the third phase was prevented.

In experiments with varying D2EHPA ratios for thorium extracting from $\mathrm{Fe}$-free solution, 30\% of D2EHPA was determined as the most favorable concentration by considering the extracting of HREE and other impurities. Organic/Aqueous phase ratios were tested with $30 \%$ of D2EHPA and $1 / 3 \mathrm{O} / \mathrm{S}$ ratio with $94 \%$ thorium extracting efficiency was determined as the most favorable ratio. The use of low-volume organic phase enabled the thorium taken into organic phase to concentrate. A more concentrated organic phase was preferred because it reduces the amount of acid used during stripping phase and the amount of chemicals to be used for precipitation.

Direct thorium stripping was not preferred as it would cause impurities to pass into the aqueous phase with thorium. In addition, scrubbing experiments were carried out for HREE and LREE that emerged as byproducts in the process. Since high acidity is needed to strip HREE forming more stable complex with D2EHPA, low concentration of $\mathrm{H}_{2} \mathrm{SO}_{4}$ has been used to scrub LREE and loss of HREE has been minimized. Then, HREE were stripped with high efficiency and low concentrations of thorium from the organic matter by using $6 \mathrm{M} \mathrm{HCl}$. The impurities in the stripped HREE were extracted with TOPO and thus, HREE were recovered.
The thorium oxalate compound obtained as a result of the precipitation was first dried at $105{ }^{\circ} \mathrm{C}$ and $\mathrm{Th}\left(\mathrm{C}_{2} \mathrm{O}_{4}\right)_{2} \cdot 2 \mathrm{H}_{2} \mathrm{O}$ was obtained. The dried solid product was calcined at $1,050{ }^{\circ} \mathrm{C}$ and the mass loss was calculated as $41.7 \%$. This ratio is consistent with the theoretical mass loss in transition from thorium oxalate $(444.107 \mathrm{~g} / \mathrm{mol})$ to thorium oxide $(264.037$ $\mathrm{g} / \mathrm{mol}$ ). The final product was subjected to ICP-OES analysis by dissolving it with four different acids and the exact values of the impurities were calculated.

\section{Results}

A process has been designed to produce high purity thorium oxide from leach liquors of complex ores. Adogen 464, which has the highest separation factors, is the most favorable among the solvents tested for iron extracting. $20 \%$ of Adogen 464 was chosen as the most suitable rate. In addition to iron, impurities such as $\mathrm{Cu}, \mathrm{Ti}, \mathrm{V}$ and $\mathrm{U}$ that may cause problems in further stages were also extracted at certain rates.

The most favorable parameters for the extracting phase were determined as $0.9 \mathrm{M}(30 \%)$ D2EHPA and $1 / 3$ organic/aqueous phase ratio. The separation factor between Th-HREE is around 200 for these parameters. Stoichiometry of Th-D2EHPA complex was found as 1:2.8 with slope calculation. Some of the HREE, $\mathrm{Cu}$, $\mathrm{Ti}, \mathrm{V}$ and $\mathrm{U}$ were extracted with thorium.

During the first scrubbing phase, LREE were scrubbed by using $0.25 \mathrm{M}$ of $\mathrm{H}_{2} \mathrm{SO}_{4}$. In the second stage, HREE were scrubbed with $6 \mathrm{M} \mathrm{HCl}$. Thorium was stripped with $6 \mathrm{M} \mathrm{H}_{2} \mathrm{SO}_{4}$ from the scrubbed organic phase and then thorium was precipitated with oxalic acid. After drying and calcination processes, thorium oxide was characterized by ICP-OES and SEM-EDS. $\mathrm{ThO}_{2}$ purity was measured as $99.23 \%$ by measuring with ICP-OES device.

This method can be used for the production of high purity $\mathrm{ThO}_{2}$ from mineralization containing rare earth elements and is consistent with further studies that are going to be performed by using leach liquor.

\section{Acknowledgement}

This study was supported by the General Directorate of Mineral Research and Exploration within the scope of Scientific Research Projects. Authors would like to thank to Mehmet Ergin from 
Cytec Inc. Turkey for his advices about the solvents and Ufuk Kibar, Nihal Görmüş and Gökçe Gürtekin from General Directorate of Mineral Research and Exploration for their contributions with SEM-EDS analyses and images.

\section{References}

Ali, A.M.I., El-Nadi, Y.A., Daoud, J.A., Aly, H.F. 2007. Recovery of thorium (IV) from leached monazite solutions using counter-current extraction. International Journal of Mineral Processing 81, 217-223.

Aybers, M.T. 1998. Kinetic study of the thermal decomposition of thorium oxalate dihydrate. Journal of Nuclear Materials 252, 28-33.

Bahri, C.N.A.C.Z., Ismail, A.F., Majid, A.A., Ruf, M.I.F.M., Al-Areqi, W.M. 2018. Extraction and purification of thorium oxide $\left(\mathrm{ThO}_{2}\right)$ from monazite mineral. Sains Malaysiana 47, 1873-1882.

Cox, M. 2004. Solvent Extraction in Hydrometallurgy, in: Solvent Extraction Principles and Practice, Revised and Expanded. CRC Press, 466-515.

D’Eye, R.W.M., Sellman, P.G. 1955. The thermal decomposition of thorium oxalate. Journal of Inorganic and Nuclear Chemistry 1, 143-148.

Demol, J., Ho, E., Senanayake, G. 2018. Sulfuric acid baking and leaching of rare earth elements, thorium and phosphate from a monazite concentrate: Effect of bake temperature from 200 to $800^{\circ} \mathrm{C}$. Hydrometallurgy 179, 254-267.

Dinkar, A.K., Singh, S.K., Tripathi, S.C., Verma, R., Reddy, A.V.R. 2012. Studies on the Separation and Recovery of Thorium from Nitric Acid Medium using (2-ethyl hexyl) Phosphonic Acid, Mono (2-ethyl hexyl) Ester (PC88A)/N-Dodecane as Extractant System. Separation Science and Technology 47, 1748-1753.

Ditz, R., Sarbas, B., Schubert, P., Töpper, W. 1990. Thorium, Natural Occurrence, Minerals (Excluding Silicates), 8th ed, Gmelin Handbook of Inorganic Chemistry. Springer Berlin Heidelberg, Berlin, Heidelberg.

Du, H.S., Wood, D.J., Elshani, S., Wai, C.M. 1993. Separation of thorium from lanthanides by solvent extraction with ionizable crown ethers. Talanta 40, 173-177.

Güneş, H., Obuz, H.E., Alkan, M. 2019. Selective Precipitation of Th and Rare-Earth Elements from $\mathrm{HCl}$ Leach Liquor, in: Minerals, Metals and Materials Series. Springer International Publishing, ss. 81-86.

Kaya, M., Bozkurt, V. 2003. Thorium as A Nuclear Fuel, içinde: 18th International Mining Congress and Exhibition of Turkey. ss. 572-578.

Li, D., Zuo, Y., Meng, S. 2004. Separation of thorium(IV) and extracting rare earths from sulfuric and phosphoric acid solutions by solvent extraction method. Journal of Alloys and Compounds 374, 431-433.

Mishra, R.K., Rout, P.C., Sarangi, K., Nathsarma, K.C. 2011. Solvent extraction of $\mathrm{Fe}(\mathrm{III})$ from the chloride leach liquor of low grade iron ore tailings using Aliquat 336. Hydrometallurgy 108, 93-99.

Nasab, M.E., Sam, A., Milani, S.A. 2011. Determination of optimum process conditions for the separation of thorium and rare earth elements by solvent extraction. Hydrometallurgy 106, 141-147.

Ritcey, G.M., Ashbrook, A.W. 1979. Solvent extraction: principles and applications to process metallurgy. Elsevier Scientific Pub. Co.

Sahu, K.K., Das, R.P. 1997. Synergistic extraction of iron(III) at higher concentrations in D2EHPATBP mixed solvent systems. Metallurgical and Materials Transactions B: Process Metallurgy and Materials Processing Science 28, 181-189.

Saji, J., Reddy, M.L.P. 2001. Liquid-liquid extraction separation of iron(III) from titania wastes using TBP-MIBK mixed solvent system. Hydrometallurgy 61, 81-87.

Salehuddin, A.H.J.M., Aziman, E.S., Bahri, C.N.A.C.Z., Affendi, M.A.R.A., Idris, W.M.R., Ismail, A.F. 2019. Effectiveness study of thorium extraction from hydrochloric acid using di (2-Ethylhexyl) phosphoric acid (D 2 EHPA). Sains Malaysiana 48, 419-424.

Wang, Y., Huang, C., Li, F., Dong, Y., Sun, X. 2017. Process for the separation of thorium and rare earth elements from radioactive waste residues using Cyanex ${ }^{\circledR} 572$ as a new extractant. Hydrometallurgy 169, 158-164.

Y1ld1z, N., 2017. Uranyum Toryum. Chamber of Mining Engineers of Turkey, Ankara.

Zhang, Y., Xu, Y., Huang, X., Long, Z., Cui, D., Hu, F. 2012. Study on thorium recovery from bastnaesite treatment process. Journal of Rare Earths 30, 374-377. 